\title{
LUANDA E FEIRA DE SANTANA: UMA COMPARAÇÃO LINGUÍSTICA NA VARIAÇÃO NA CONCORDÂNCIA VERBAL DE NÚMERO COM OS VERBOS TER E HAVER EM CONSTRUÇÕES EXISTENCIAIS Nathalia dos Santos Dantas ${ }^{1}$; Silvana Silva de Farias Araujo².
}

1. Bolsista PIBIC/CNPq, Graduanda em Licenciatura em Letras com Inglês, Universidade Estadual de Feira de Santana, e-mail: nathi.ndantas@gmail.com

2. Orientadora, Departamento de Letras e Artes. Universidade Estadual de Feira de Santana, e-mail: silvana.uefs.2014@gmail.com

PALAVRAS-CHAVE: Verbos ter e haver; Sociolinguística; Feira de Santana - Angola

\section{INTRODUÇÃO}

Buscando reafirmar a importância de estudos comparativos que englobem variações do português que não sejam a europeia, privilegiada por tantas outras pesquisas, e focalizando assim, no estudo de uma variação de indiscutível influência no português brasileiro, como é o caso do português africano, realizou-se na presente pesquisa um estudo comparativo entre o Português falado em Luanda - Angola e em Feira de Santana - Bahia. A pesquisa pautou, inicialmente, o fenômeno da concordância verbal de número dos verbos ter e haver, quando empregados em construções existenciais, com o sintagma nominal seguinte ao verbo (objeto direto), porém, após termos nos deparado com o uso majoritário destas formas verbais no singular, o objeto de estudo da pesquisa foi redirecionado para a investigação da variação entre os verbos ter e haver e em quais estruturas ocorria esta variação. Assim sendo, a pesquisa buscou contribuir de forma clara para a discussão sobre formação do português brasileiro, salientando a importância do contato linguístico para esta formação, visto que, ao contrário de pesquisas que relacionam o português europeu (PE) e a sua variação brasileira (PB), as pesquisas que relacionam a variação brasileira e angolana são escassas, e com o adendo da investigação linguística em uma cidade brasileira a pesquisa tornou-se mais rica e completa.

\section{METODOLOGIA}

Adotou-se o modelo teórico-metodológico da Teoria da Variação e Mudança Linguística, também denominada Sociolinguística Quantitativa, com base nas formulações de Weinreich, Labov e Herzog (2006[1968]) e Labov (2008 [1972]). Esse foi o modelo adotado em função de ser considerado teoricamente coerente $\mathrm{e}$ metodologicamente eficaz para a descrição de uma comunidade de fala numa perspectiva Variacionista.

Os dados da pesquisa foram levantados em entrevistas sociolinguísticas do tipo DID (diálogo entre informante e documentador), gravados na região urbana do município de Luanda, capital de Angola e também a capital da Província com o mesmo nome, Luanda. Tais dados encontravam-se previamente analisados ao começo deste segundo ano de pesquisa desenvolvido.

Os dados que constituíram o corpus feirense da pesquisa foram levantados em vinte e quatro entrevistas, pertencentes ao acervo do Projeto Em busca das raízes do português brasileiro' ao qual o Projeto "A concordância verbal em Luanda-Angola: elementos para a discussão sobre a formação do português brasileiro (RESOLUÇÃO

\footnotetext{
1 Projeto Em busca das raízes do português brasileiro. Informações disponíveis em: <http://www2.uefs.br/nelp/angola/index.html $>$. Acesso em 29. mar.2014.
} 
CONSEPE 058/2014 - 18/07/2014)" está vinculado. Ambos os projetos estão sediados no Núcleo de estudos da língua Portuguesa (NELP) da UEFS.

As entrevistas de Feira de Santana foram estratificadas e subdivididas da seguinte forma: sexo, faixa etária e escolaridade. Após o levantamento das ocorrências nas entrevistas e seleção das variantes (2 linguísticas e 3 socioculturais), foi utilizada chave de codificação dos dados. Com os dados já codificados, ficou a cargo do programa computacional GoldVarb X (SANKOFF, et al., 2005) a realização do tratamento quantitativo das ocorrências encontradas. Após coleta dos resultados emitidos pelo programa supracitado, a análise destes dados coube ao pesquisador.

\section{RESULTADOS}

Procedeu-se a uma pesquisa em torno dos verbos ter e haver, com o objetivo inicial de investigar em quais tipos de estruturas ocorriam as formas verbais com esses dois verbos no português feirense, visto que os dados do português luandense já encontravam-se analisados. Foram consideradas as seguintes estruturas:

Quadro 1: Estruturas investigadas acerca do uso dos verbos ter e haver no português feirense

\begin{tabular}{|l|}
\hline $\begin{array}{c}\text { Estruturas investigadas acerca da } \\
\text { variação dos verbos ter e haver }\end{array}$ \\
\hline Posse \\
\hline Tempo composto \\
\hline Modal \\
\hline Funcional \\
\hline Existencial \\
\hline Tempo decorrido \\
\hline
\end{tabular}

A distribuição dos dados é apresentada a seguir. Como se observa na tabela 1 , apenas nas estruturas existenciais e existenciais indicando tempo decorrido verifica-se um processo de variação estruturada com regras, de fato, variáveis. No entanto, por se tratar de uma pesquisa comparativa, considerou-se coerente focalizar de maneira mais aprofundada a variação em comum das duas variações do português (existencial).

Tabela 1: Verbos ter e haver no português feirense em diferentes tipos de estruturas

\begin{tabular}{l|c|c|c|c}
\hline & \multicolumn{2}{|c|}{ Ter } & \multicolumn{2}{c}{ Haver } \\
\hline & $\begin{array}{c}\text { N de } \\
\text { ocor./Total }\end{array}$ & Percentual & $\begin{array}{c}\text { N de } \\
\text { ocor./Total }\end{array}$ & \\
\hline Posse & $983 / 983$ & $100 \%$ & $0 / 983$ & $0 \%$ \\
\hline Tempo composto & $100 / 100$ & $100 \%$ & $0 / 100$ & $0 \%$ \\
\hline Modal & $273 / 273$ & $100 \%$ & $0 / 273$ & $0 \%$ \\
\hline Funcional & $54 / 54$ & $100 \%$ & $0 / 54$ & $0 \%$ \\
\hline Existencial & $981 / 1040$ & $\mathbf{9 4 \%}$ & $59 / 1040$ & $\mathbf{6 \%}$ \\
\hline Tempo decorrido & $35 / 66$ & $\mathbf{5 3 \%}$ & $31 / 66$ & $\mathbf{4 7 \%}$ \\
\hline
\end{tabular}

Dos grupos controlados neste estudo, todos foram selecionados pelo Goldvarb $\mathrm{X}$ como relevantes para a implementação do verbo ter existencial. O input inicial de aplicação da regra de ter existencial foi 0,42 , o input final foi 0,41 , o nível de significância foi 0,001 e o log likelihood foi -228.952. A seguir, será apresentada (seguindo a ordem das variáveis controladas) a discussão dos resultados encontrados no 
português feirense com comparações aos resultados previamente analisados do português de Luanda. Começando com as variáveis linguísticas, temos:

\section{Tempo verbal}

Os resultados de Feira de Santana apontam para um maior favorecimento da forma verbal ter nos tempos verbais presente e pretérito imperfeito, alinhando-se ao português falado em Luanda apenas em um destes tempos verbais (pretérito imperfeito). As pesquisas realizadas em ambas as cidades destoam do que demonstra a literatura de Callou e Avelar (2000, p.91), que constatam que construções no passado favorecem o uso da forma verbal haver. Porém, vale ressaltar que, corroborando com a pesquisa de Marins (2013, p. 69), a qual afirma o favorecimento da norma haver no pretérito perfeito, os resultados da variação feirense divergirão dos encontrados na variação luandense, pois, ao passo que no primeiro há um desfavorecimento do uso do ter, no segundo o favorecimento se mostra bastante acentuado. Portando, em uma mesma variável, ora o PL e o PF se aproximam ora se afastam.

\section{Natureza do argumento interno}

Embora tal variável tenha sido descartada pelo Golvarb $\mathrm{X}$ dos estudos com o português luandense por motivos de relevância, na variação feirense os resultados demonstram um favorecimento da forma verbal ter quando o argumento interno possui valor semântico de lugar (espaço físico) ou humano, e expressam o desfavorecimento de tal forma verbal em estruturas com argumento interno de valor abstrato e evento (nesta última o verbo ter poderia ser substituído pelo verbo acontecer).

\section{Sexo}

Ao examinar os resultados obtidos com esta variável, pode-se afirmar um favorecimento da forma verbal mais inovadora ter por falantes do sexo feminino, algo que contraria a literatura de SCHERRE e NARO (1998) que, ao se referir à variação linguística no sexo feminino, afirma que as mulheres, por "quebrarem" menos as regras sociais estabelecidas, são, em particular, mais sensíveis às normas de prestígio.

\section{Escolaridade}

O controle da variável escolaridade revelou um comportamento diferenciado no uso dos verbos ter e haver a depender da escolaridade do informante. A partir da interpretação dos resultados, foi possível dizer que esta variável aproxima as duas variações do português, visto que tanto no português feirense, quanto no português luandense, o favorecimento da forma verbal ter ocorre apenas entre os falantes de escolaridade baixa ou nula, corroborando também com a tese sob a qual tal variável foi controlada.

\section{Faixa etária}

Por meio do controle desta variável é possível traçar uma projeção histórica, baseada no binômio variação-mudança, acerca do fenômeno de variação em questão. Acerca dos dados observou-se que, na variação feirense, o uso da forma verbal ter é favorecido nas faixas I e III, enquanto na variação luandense, este favorecimento se concentra nas faixas I e II (sendo mais acentuado entre falantes da faixa mais jovem). Portanto, sugere-se que, enquanto os dados do português luandense insinuam uma mudança em progresso (concorrência entre as variantes, com tendência de permanência de apenas uma delas), os dados do português feirense, por sua vez, refletem uma variação estável (coexistência de formas intercambiáveis no sistema linguístico). 


\section{CONSIDERAÇÕES FINAIS}

Após a análise dos dados e das variantes controladas no presente estudo, é possível constatar que ora o português feirense se aproxima do luandense, ora ele se afasta. Retirando os exemplos das próprias análises feitas, pode-se destacar 3 variáveis que atuam na variação: a primeira diz respeito à variável faixa etária, nesta variável pode-se constatar um afastamento completo acerca da interpretação dos resultados, visto que, enquanto os resultados do português luandense sugerem uma mudança em curso, os do português feirense já sugerem uma variação estável; contudo, apenas futuras pesquisas possibilitarão investigar se a mudança em curso luandense resultará, posteriormente, em uma variação estável também. A segunda já demonstra uma sincronia das variações pesquisadas, tratando-se da variável escolaridade, pôde-se constatar que tanto no português luandense quanto o feirense favorecem o uso da forma verbal ter quando se trata de falantes de baixa (ou nula) escolaridade. O terceiro exemplo, que diz respeito à variável tempo verbal, nos demonstra a complexidade da comparação destas duas variações, ao passo em que, na mesma variável, o português falado em Feira se Santana se aproxima e se afasta do português falado em Luanda e da literatura.

\section{REFERÊNCIAS}

CALLOU, Dinah Maria Isensee; AVELAR, Juanito Ornelas de. Sobre ter e haver em construções existenciais: variação e mudança no português do Brasil. Gragoatá (UFF), UFF, v. 9, p. 85-100, 2000.

LABOV, William. 2008. Padrões sociolingüísticos, Tradução M. Bagno, M. M. P. Scherre e C. R. Cardoso, São Paulo, Parábola Editorial.

MARINS, Juliana Esposito. Ter, haver e existir: a representação do sujeito pronominal nas construções existenciais numa perspectiva diacrônica. 2013. Tese (Doutorado em Letras Vernáculas) - Universidade Federal do Rio de Janeiro. Rio de Janeiro, 2013.

SANKOFF, David; TAGLIAMONTE, Sali; SMITH, Eric.Goldvarb X: Computer program. Departament of Linguistics, University of Toronto, Canada.Disponível em <http://individual.ca/tagliamonte/goldvarb/GV_index.htm. 2005> Acesso em: 26. jul. 2017.

SCHERRE, M. M. P. \& NARO, A. J. Sobre a concordância de número no português falado do Brasil. In Ruffino, Giovanni (org.) Dialettologia, geolinguistica, sociolinguistica. (Attidel XXI Congresso Internazionale di Linguistica e Filologia Romanza) Centro di Studi Filologici e Linguistici Siciliani, Universitá Di Palermo. Tübingen: Max Niemeyer Verlag, 5:509-523, 1998.

Weinreich, Uriel, William Labov e Marvin Herzog. 2006 [1968]. Fundamentos empíricos para uma teoria da mudança linguística, Tradução de M. Bagno; revisão técnica C. A. Faraco; posfácio de M. da C. Paiva e M. E. L. Duarte, São Paulo, Parábola Editorial. 